\title{
Persecutory Guilt, Surveillance and Resistance: the emotional themes of early childhood educators
}

\author{
SAMARA MADRID \\ Elementary and Early Education Department, \\ University of Wyoming, Laramie, USA \\ MAYLAN DUNN-KENNEY \\ Department of Teaching and Learning, \\ Northern Illinois University, DeKalb, USA
}

\begin{abstract}
This research examines the emotional themes and discourse of emotion of early childhood educators using a post-structuralist theoretical framework of emotion. The data selected and analyzed is taken from 4 two-hour discussion groups that were conducted over an eight-week period with four female early childhood educators. The emotional themes and patterns that emerged from the discussion groups and artifacts, teacher journals, and follow-up interviews were analyzed and then followed with a micro-level analysis. The findings revealed that the three most common emotion words discussed were 'stress', 'worry', and 'frustration', which were linked to surveillance and a discourse around persecutory guilt through institutional and relational systems, fostering implicit resistance among participants.
\end{abstract}

I really struggle with teaching first and second grade ... I don't have my early childhood degree ... I feel like I'm always balancing what's appropriate for them but then, at the same time, what they're gonna be tested on in third grade. (Mary, field notes, March 2008)

\section{Teacher Emotion: a post-structural perspective}

Emotions are part of teaching. Recently, researchers have examined teaching as emotional labor (Colley, 2006), have analyzed emotion as an essential part of teachers' professional identity construction (Zembylas, 2003), and have explored teacher emotion in order to understand the complexity of socially just classroom practice (Chubbuck \& Zembylas, 2007). Traditional psychological research that has examined emotion and teacher education is grounded in the notion that emotion is a psychological internal construct that is contained, regulated and managed by the teacher in the classroom context. Emotion, however, is not easy to define as the definition of emotion will vary depending upon the theoretical framework. Because of this difficulty, we draw upon Boler's definition of emotion for this study:

Emotions are in part sensational, or physiological: consisting of the actual feeling - increased heartbeat, adrenaline, etc. Emotions are also 'cognitive' or 'conceptual': shaped by our beliefs and perceptions. There is, as well, a powerful linguistic dimension to our emotional awareness, attributions of meanings, and interpretations. (Boler, 1999, p. xix)

In this statement, Boler defines emotion both as physiological and cognitive. Emotions do not just happen upon us or well up within us. Rather, they are constructed through our beliefs and perceptions about the world and, as such, are in part cognitive judgments linked to our social, cultural and linguistic realties and interactions. In her research, Boler further draws upon a post-structuralist 
definition of teacher emotion, moving from the dominant assumption that emotion is an internal psychological construct to unpacking how emotion is socially constructed through language and discourse. In particular, this framework suggests that teacher emotions are not separate and stable constructs but rather are fluid constructions that are constantly in flux, with the central argument that 'emotion is a discursive practice' and 'provides a useful theoretical tool in analyzing the place of emotion in the construction of teacher identity' (Zembylas, 2005, p. 937).

The purpose of this study is to uncover teachers' emotional themes and analyze how they are related to the discourse of emotion for early childhood educators using a post-structuralist definition of emotion. More specifically, we are interested in how emotional themes are related to the discourse of emotion within early childhood education. An emotional theme is viewed as a pattern of talk about specific emotions within the data, while the discourse of emotion is the linguistic as well as the political and social implications of such a theme. The term discourse of emotion captures the social and political nature associated with emotional practices, and how emotions are embedded in societal norms and related to power, language, and ideology (Lutz, 1988, 1990; Boler, 1999; Gergen, 1999; Burr, 2003; Ahmed, 2005; Zembylas, 2005, 2007).

The discourse of emotion defines not only how, when, why and where one can display emotions, but also how emotions are situated discursively and bound to social identities and power relations. Zembylas (2005, p. 954) argues that 'one has to explore the use and meaning of emotional rules against the backdrop of school structures and norms'. When emotions are positioned as internal states that need to be regulated or monitored by the teacher, power relations embedded within emotional discourses are not visible. In contrast, a discursive understanding of emotion uncovers how emotion is interwoven with issues of power, identity, and resistance. Emotions are not neutral to the political and institutional systems that define appropriate and correct emotional display. Emotions, from this perspective, are not simply internal mechanisms that a teacher expresses and reflects on, but rather are social constructs that exist in systems of relationships constructed by, and through, language and discourse.

There are not explicit rules that determine what emotion is right or wrong to display as a teacher (i.e. a manual or formal instruction about how to behave emotionally). Yet, teachers constantly engage in the social practice of talking with other teachers about appropriate and inappropriate emotion in the classroom, noting that teaching requires 'a display of professionalism' (Zembylas, 2005, p. 941), which is linked to self-control and neutrality of emotion (i.e. not showing emotion). Thus, to be professional means to have self-control and display neutral affect in the classroom. For example, Boler posits that contradictory rules of emotional expression function to uphold the dominant culture's hierarchies and values:

A primary goal of education is to discipline young people's social and moral values and behaviors. This moral conduct is inextricably tied to emotional control. Although social control is directed at all who participate in education - teachers, administrators, and students - the discourses of emotion in education are most consistently present and visible in relation to women. Women are the repository in Western Culture, while in their role as schoolteacher they are simultaneously assigned to prepare moral citizens and expected to be the 'guardian against the irrational'. (Boler, 1999, p. 31)

This statement suggests that women in educational settings have been positioned as the moral regulators of emotion in the classroom. Teachers are taught to monitor, regulate, control, contain, and 'put a lid on' emotions that do not fit with 'normal' ways of being and feeling. Boler continues to add that emotional regulation stems from pastoral power and the dichotomization of emotions as good/bad, male/female, and rational/irrational. Through the internalization of society's norms and beliefs about proper emotional display rules, teachers construct images about their own emotional behavior as related to being a professional.

Teachers' roles require that they regulate their own emotions in order to properly regulate the emotions of children (Cannella, 2002), setting up a situation in which teachers are responsible for handling the emotional 'problems' that may arise in the systems of relationships within the school (i.e. with children, parents, colleagues). Through discourses about teacher professionalism, which position the adult as powerful and the child as needy, educational emotional 'problems' (which are, by definition, anything outside the norms established by dominant discourses) are firmly attached to teacher identity. A teacher is positioned as 'good' or 'bad' according to his or her 
ability to control and regulate emotional rules and displays defined as problematic, both for themselves and the children they teach.

MacNaughton (2005) adds to our understanding by noting that conceptions about the 'good' early childhood educator are grounded in dominant discourses and inseparable from power and politics. Using a Foucauldian perspective, she asserts that multiple contesting and contrasting discourses operate in the classroom to make ways of being, doing, and feeling political in nature. The emotional lives of educators are not static, linear, or neutral, but rather are complex, messy, dynamic, and political. Chubbuck \& Zembylas (2007) describe the emotional life of a first-year teacher as complex and ambivalent. As more and more teachers are being pressured to conform to linear and standardized regimens of knowledge, studies are revealing how teachers are feeling constrained, scrutinized, and under surveillance by the political standards and power structures imposed upon them in this era of accountability (Brown \& Sumsion, 2007).

Love of children and the emotional satisfaction of teaching are thought to be the main reasons why people do the hard and low-paid work of educating young children. In fact, many of the first US early childhood teachers worked for free as a form of service with the reward being framed as spiritual and emotional in nature rather than monetary. In keeping with these assumptions and the unique history of early childhood education practice, emotion research in early childhood education has traditionally focused on the emotions of 'caring' and 'love' as pedagogical tools (Noddings, 1984; Goldstein, 1997), or even as the 'product for sale' in the emotional labor of caring for children (Colley, 2006). In the present cultural and political climate, however, the early childhood teacher is in a troubled position with regard to the process of selfformation of a professional emotional identity (Zembylas, 2003), due to the current standards-based accountability discourse. Given this, there is a need to explore further the role of emotion in the lives of early childhood educators using a view of emotion that is not based solely on the concept that emotion is an internal psychological phenomenon. Thus, this study aims to uncover the emotional themes of early child educators and how they are related to the discourse of emotion. For example, how are emotions shaped by and reflected in teachers' professional identities? How is the discourse of emotion related to shifting definitions of the 'good teacher' and notions of teacher accountability?

It is important to note that we do not aim to debate the existence of a biological aspect of emotion. Moreover, we will not assume that emotional identities are separate from professional identities. Rather, our goal is to illustrate how emotions are also discursively located and embedded within the social and cultural practices of being a professional (i.e. teacher), and shaped by the current climate of professionalism. Markus \& Kitiyama suggest:

We are not assuming that emotions are not felt or that they are not biological or even universal for that matter. The main argument is that emotions are not neutral to the social systems that exist in a culture. The ways emotions are organized within a particular culture are very much dependent upon the moral and social order, as well as ideological and political systems.

Emotions, regardless of the location, are part of a social system, which occurs and is shaped by social action and through social relationships. In short, emotions are social actions. (Markus \& Kitiyama, 1994, p. 6)

Teachers strive to interpret and make sense of their emotional worlds as professionals. This article presents an analysis of early childhood educators' emotional themes during discussions about emotions in the classroom. By examining how teachers discuss emotions, and the themes associated with these emotions, we can also make visible the micro-level discourse of emotion linked with such themes. The following questions guided the analyses: (1) 'What are the discourses of emotion associated with early childhood educators?' and (2) 'How are the discourses of emotion used as a site of social control?'

\section{Methodology}

Procedure

Four white female early childhood educators from a mid-sized Midwestern town in the United States and two white female researchers, who acted as participant observers (Spradley, 1980), 
participated in 4 two-hour discussion groups over an eight-week period (spring semester 2007), allowing for an in-depth and focused examination of the participants' thoughts and language usage about emotion (Ryan \& Lobman, 2007).

In order to elicit participants, the study was announced in Master's-level courses at a university and through an email sent by the university partnership office to participating schools. We were looking for typical, engaged teachers who were currently working in the field. All of the teachers in the study worked in an early childhood setting (birth through age eight) and all had five plus years of teaching experience. The participants needed to agree to keep journals about their emotions in the classroom during the same eight-week period. Discussions were audio- and videotaped, and the tape recordings were then transcribed. One-hour follow-up interviews were conducted with each individual participant as a way to build trustworthiness in the data and the researchers' interpretations. Artifacts collected during the discussion groups include individually created images representing an emotion in the classroom, individual drawings of the 'good-enough teacher', individual written metaphors about the relationship between teachers' and children's emotions, and a collaborative categorization of emotion words.

The following questions were presented at the beginning of each of the four discussion group sessions; participants, however, were free to change the discussion and were not redirected if they veered away from the question:

1. Discussion session 1: 'What emotions do you see as being part of your classroom life?'

2. Discussion session 2: 'Can you describe a time when you have observed a relationship between your emotions and the emotions of the children in the classroom?'

3. Discussion session 3: 'Describe the emotions of the perfect teacher/Describe the emotions of the good-enough teacher.'

4. Discussion session 4: 'Describe the learning associated with the emotions that you see as being part of your classroom life.'

These discussions were used as the primary method to gather data because of the exploratory nature of the research questions. It was our goal to create a space where educators could talk about and reflect on their emotional lives as professionals with other professionals. We purposefully kept the groups small and conducted this research over only an eight-week period to create familiarity among the participants and allow for in-depth responses to emerge. While the data does not provide a classroom-based, behavioral account of emotions, it provides insight into how teachers construct and position themselves as emotional beings, as well as how teachers take up and resist dominant discourse structures through this particular context (i.e. teacher discussion) (Davies $\&$ Harré, 1990).

\section{Data Analysis}

The data analysis occurred in three phases. First, a thematic analysis was conducted to uncover general emotional patterns and themes. Next, we did a word count (combing the data to count the emotion words used). Lastly, we conducted a micro-level analysis of the transcripts. The analysis was conducted first by transcribing the four discussion groups. The transcripts were reviewed multiple times by the two researchers and then a search for further examples and counter-examples of the emotions discussed and the themes associated with the emotion/feeling was used to formulate general themes and patterns arising from the data (Spradley, 1980). In order to verify these patterns and themes, the data was next examined at the level of the emotion words used. We reviewed a list of 50 emotion words generated at the beginning of the first focus group, prompted by the question, 'What emotions do you see as being a part of your classroom life?' Those 50 words were then used as a guide to comb the texts from all four focus group sessions. A table was then created listing each emotion word and where and when it occurred in the transcript (i.e. the emotion word and the dialogue around it). In our analysis, we counted the emotion words and also noted the times when the participants used the term 'I feel'. While academic writing distinguishes between emotion and feeling (Lutz, 1988), we noticed that in the interviews, participants using their everyday language used the terms almost interchangeably. After the thematic analysis had been conducted, the researchers narrowed their focus to examine these specific texts in order to 
conduct a detailed micro-level analysis, which centered on uncovering how the participants used language to take up and/or resist dominant discourses of emotion (Davies \& Harré, 1990).

\section{Findings}

The Theme of Surveillance

The theme of surveillance emerged as a dominant concern of the teachers in the data resources/texts, connected to the fear of being policed by institutional and relational systems within their settings. We considered this an emotional theme as it was linked to a pattern of talk around stress, frustration, and worry. Thus, it was the frequency of emotion words associated with concerns about surveillance that made this a salient theme. Four types of surveillance were identified: institution, parent, child, and colleague. The four types of surveillance were then categorized into two types: institutional (i.e. governing bodies) and relational (i.e. relationships with parents, children, and colleagues). Table I provides an example of institutional and relational surveillance taken from the discourse of two of the study participants.

\begin{tabular}{ll}
\hline Surveillance & Example emotion statement \\
\hline Relational & $\begin{array}{l}\text { Fran: I would say worried [long pause], sort of like, sometimes you're like worried [if someone } \\
\text { doesn't] be where they're supposed to be [by the end of the year]. You worry about what the } \\
\text { kindergarten teacher's gonna think. What we did with them. }\end{array}$ \\
Institutional & $\begin{array}{l}\text { Joy: I was talking with some people from my district, some special education teachers, and } \\
\text { they don't even touch the children. They're told they can't because of liability or just, you } \\
\text { know, don't wanna be put in a situation where someone could accuse you of something. So } \\
\text { they just don't do it. That's so sad! }\end{array}$ \\
\hline
\end{tabular}

Table I. Example of institutional and relational surveillance.

Surveillance is defined as 'monitoring' or 'watching over' a person or a group of people. Boler (1999) notes that surveillance is related to the internalized phenomenon of fear. She suggests the fear of being under surveillance 'forces individuals to "internalize" the sense of being watched and thus police themselves. Surveillance, in turn, capitalizes on internalized fear and relies on confession and self-blame' (Boler, 1999, p. 22). Given the frequency, complexity, and embeddedness of the emotion words linked to this theme in the data, the researchers narrowed the scope to conduct a detailed micro-level analysis of transcripts centered on surveillance (Bloome et al, 2008). Thus, a broad thematic analysis was conducted to determine central patterns in emotion talk and then a more fine-grained examination of the transcripts was used for micro-level analyses to make visible how language was used within specific transcripts where the theme occurred.

The issue of surveillance arose in the discussions without our solicitation or prompting and was confirmed in the follow-up interviews as a common issue in their everyday emotional lives as teachers. In fact, even though we acted as participant observers during the discussion groups, the theme of surveillance and its association with the most frequently occurring emotion words was not apparent until the formal data analysis was conducted. While the emotions of satisfaction, appreciation, joy, and love were also discussed, the emotions of stress, worry, frustration, sacred, and anger were the five most frequently raised emotions in our four discussion sessions. Emotion words from the list generated during the first focus group were used to scan the text from all four sessions, resulting in the following list of frequently named emotions: stress: 16; worry: 13; frustration: 12; scared: 10; and anger: 9. In addition, when creating a list of emotions felt in the classroom during the first focus group, the teachers noted that 'frustration' should be at the top of the list of teachers' emotions.

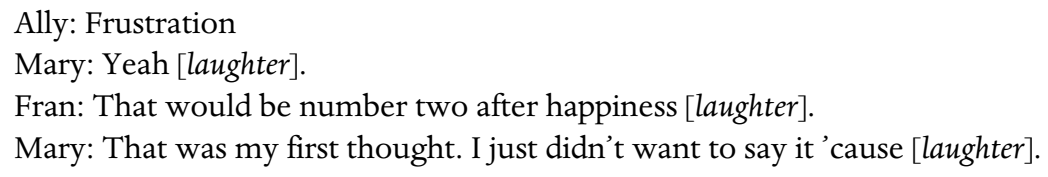


Interestingly, the top three emotion words (i.e. stress, worry, and frustration) have been associated with persecutory guilt, an emotion noted by Hargreaves (1994) as a tool to police the lives of teachers through increasing pressures of accountability.

It must be noted that three out of the four participants' narrative comments are presented below. Joy, one of the four participants, did not contribute verbally to discussions to the extent of the other three participants. While Joy was actively present, she did not present any long narratives about her classroom life. Joy did not appear uncomfortable or unengaged in the conversation, but also did not contribute lengthy narratives about classroom life as compared to the other three participants. She did, however, insert comments in relation to others' stories and often took on a supportive listening role as the oldest and most veteran teacher (with 30 years of experience). One of the researchers had the opportunity to informally observe Joy in various settings within the community, as well as in her classroom, and noted that she held the same conversational style in these interactions, often taking on the listening and supporter role during conversations both with adults and children. Given this, the following micro-level analysis contains narrative excerpts from three of the four teachers.

\section{Institutional Surveillance: 'George is checkin' on ya!!'}

In each of the discussion groups, comments related to the pressures of standardized testing and accountability were made at some point by each of the teachers. The most intense complaints about accountability and its intensification were directed at various forms of testing and the pressures of standards, which were then met with signs of agreement (i.e. comments and laughter) from the other participants when the issue was raised. For example, when discussing emotion in the classroom during the first discussion group in March 2008, Mary notes:

I feel like I'm always balancing what's appropriate for them but then, at the same time, what they're gonna be tested on in third grade ... and now we're doing CBMs [Curriculum Based Measurements]. I mean this, that's the, this year that's probably the feeling I feel, 'cause now they're looking at everybody's data. You know where every kid is.

In this statement, Mary notes her concern with testing and preparing children for the third grade, because 'they're looking at everybody's data'. The use of 'they' evokes a faceless authority and was used repeatedly by the participants to refer to governing systems of power. Joy, the teacher with the most experience, also notes how accountability and its intensification had changed the school atmosphere: 'There's more accountability than there used to be ... It's much different than when I started teaching, for sure.' Both of these issues (i.e. feeling under surveillance and increasing pressure to conform to these demands) are illustrated in the following transcript of Mary during the second discussion group, when she returned to a prior discussion about balancing what's appropriate with what is expected from institutional systems. Prior to the transcript below, the group participants had been discussing how teacher emotion affects the emotions of children in the classroom. Mary began by noting how the watchful eye (i.e. 'they') had caused her to weigh and counter children's emotional needs with their academic needs in the classroom:

1. Mary: A lot of'em have a lot of needs,

2. emotional needs.

3. I'm sorry,

4. but, yo, we have to read this book.

5. You know we have to know

6. these word wall words [laughing].

7. I care about you that much

8. that we have to just, um...

9. but it's hard,

10. it's very hard

11. when they're not ready.

12. But the, I, and I, and

13. I also think that the pressure

14. that we're under, 
15. and I just feel it more

16. and more every year.

In lines 1 and 2, Mary notes that a lot of children have needs, emotional needs. This is followed by an apology (perhaps like one she might offer to the children in lines 4-6) as she describes how the academic activities of reading and the word wall must be completed. She then suggests in line 7 that it is because '[she] cares about [them] that much'. This statement suggests that she cares about the children enough to regulate one particular aspect (i.e. emotional needs) so she can prepare them to meet the institutional regulations.

In this transcript example, the caring teacher is the teacher who monitors the children's emotions and redirects their attention to the academic standards. Interestingly, she does not state that she tends to their emotional needs because she cares about them, but rather she tends to their academic needs because she cares about them. In lines 8-16, she explains why she must ignore their emotional needs by mentioning 'it's very hard when they're not ready'. This statement could mean that it is very hard when they are not ready emotionally, or it is very hard when they are not ready academically, or both. Regardless, she notes the difficulties that exist when children are not ready to meet institutional standards.

In lines 13-16, she further notes how intensification of accountability is a reason for her inability to focus on children's emotional needs, by stating: 'I just feel it more and more every year'. Mary acknowledges that children have needs, while also noting that she has to monitor these needs because she cares about the children, suggesting a policing of emotion as well as academic content (i.e. emotion is okay sometimes but needs to be put aside to focus on reading and word walls). Mary reconciles the caring teacher position with the position of the accountable teacher who is required to meet the institutional standards and testing criteria. Mary is clearly concerned that her students will not meet regulations, which is directly linked to worries about a failure to meet what is required by the governing bodies.

The fear of failure and monitoring/evaluation of student behavior in the context of a discussion about institutional regulations are a direct function of surveillance and persecutory guilt (Hargreaves, 1994). While not explicitly stated, persecutory guilt is embedded in the discourse around the policing of student emotion in the classroom. For example, she implicitly apologizes when she states that 'we have to read this book' and 'we have to know these word wall words'. The use of 'we' within these statements implicitly indexes an apology from Mary to the students, as 'we' (i.e. she and the entire class) have no choice but to do these specific classroom actions. Furthermore, she notes that there is more and more pressure every year to have her students meet these standards:

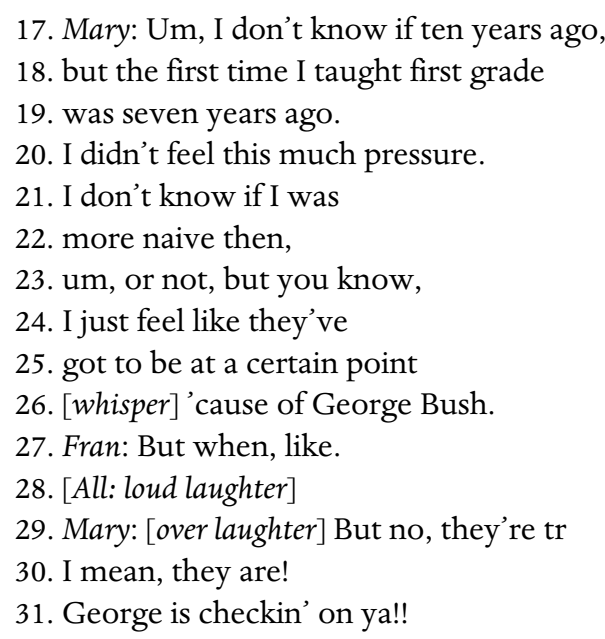

In lines 17-20, Mary again returns to the notion of intensification to justify her need to regulate the classroom. First, she attributes the change to her having been a novice in the classroom, but then suggests that she feels (now) that children have to be 'at a certain point'. In line 26 , she provides a reason for the pressure by stating that it is "cause of George Bush', which is tellingly said in a whisper (perhaps so the governing bodies will not hear?). Her use of a whisper here indicates that 
she is trying not to speak so loudly and could also indicate that, at some level, she believes that blaming George Bush for the added stress should not be spoken. Conversely, the whisper could actually also be seen as a form of resistance or rejection of the governing bodies, because a whisper allows her to speak the unspoken; to speak against those who are "checkin" on her. Participant laughter is followed by Mary mockingly saying in line 31: 'George is checkin' on ya!!' This is also a reference to the US federal No Child Left Behind Act, which mandated punitive sanctions for schools failing to meet specific levels of performance on standardized tests. In addition, despite humor, she also affirms 'they are!' to show her seriousness about this belief.

By referring to President Bush by his first name and exaggerating the personal, Mary again humorously resists the faceless surveillance of bureaucratic control by giving 'them' a name (i.e. George Bush). According to Hoy (2004), resistance is shaped by the constraint that inspires it. For example, after expressing frustration with the depersonalization and anonymity of institutional surveillance, Mary disrupts that depersonalization by using George Bush as a personal embodiment of the surveillance accompanying the accountability measures in the federal No Child Left Behind Act, which serves as resistance to the dominant discourse.

Mary then continues to take the position of being under surveillance by noting her concern about how testing data is being made public for everyone to see on paper. Not only is George "checkin", but also her school community is watching, making explicit the notion that her students (and herself via her students) are being compared to others, publicly fostering normative comparisons among children, classrooms, and teachers:

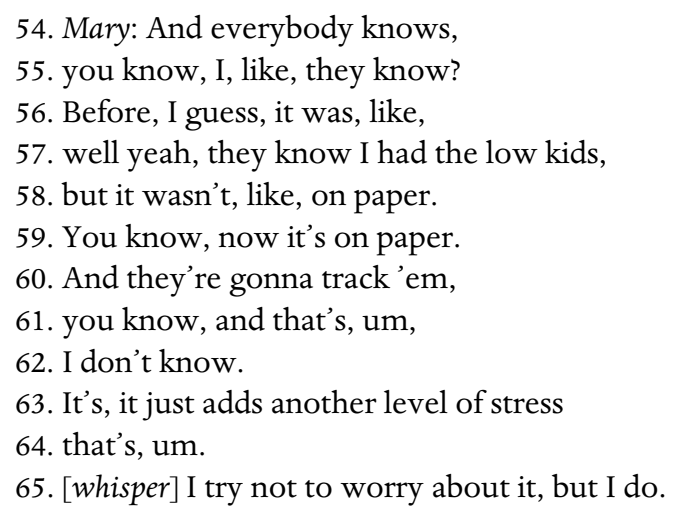

Mary notes that 'everybody knows', suggesting the issue is not simply the testing but also the knowledge that her children are the lowest. This is shared with the entire school and now it is on paper, making traceable and lasting public knowledge of what was once shared only with her colleagues (i.e. 'they know I had the low kids'); now, it is placed into an impersonal space (i.e. 'on paper'), positioning her students negatively as the low kids. In line 60 , she notes that 'they're' going to track the children, suggesting that this surveillance and monitoring will not end, as it is an ongoing public comparison of her teaching and the students which will occur over time. More importantly, her mentioning of tracking also implies that if there is an increase or decrease in scores, this will also be made public, adding another level of stress to her daily life in the classroom. She ends in line 65 with a whispered statement that she tries not to worry, but she does. Here she takes up a position associated with an emotional discourse of persecutory guilt and surveillance, fostering the self-policing of actions and inducing worry about whether or not her class will meet the institutional standards.

When exploring teacher emotion and accountability in education, Hargreaves (1994) notes that guilt is a common emotion used to police the lives of teachers. Two types of guilt tend to be prominent in the daily lives of teachers: persecutory guilt and depressive guilt. Persecutory guilt stems from not doing something that is regulated or from a failure to meet institutional standards, while depressive guilt stems from failing to meet the needs of those around them (for example, not caring for the child). Distinguishing between guilt traps and guilt trips, Hargreaves (1994, p. 142) notes that guilt traps are patterns of behavior that lead to guilt, while guilt trips are strategies used to 'deal with, deny or repair this guilt'. Accountability and its intensification, which are related to persecutory guilt, are a central component in self-policing: 'Accountability and its intensification provide a potent cocktail for inducing feelings of persecutory guilt - pervasive worries and fears 
that mounting expectations have not or will not be met' (Hargreaves, 1994, p. 3). Through guilt, teachers learn how to self-police their behavior to conform to governing bodies and regimens of knowledge that determine what it means to be an effective teacher in the era of accountability.

\section{Relational Surveillance: being incompetent}

The teachers in the discussion groups not only felt themselves to be under surveillance by the faceless 'they', but also noted how this surveillance affected their relationships with students and colleagues. In this section, we illustrate how surveillance led to worries about being incompetent and was related to relationships with children in the classroom. The following transcript is taken from Ally and occurred during the fourth discussion group session. The participants had been discussing the pressures of No Child Left Behind and how this affected their behavior in the classroom during this time of the school year (i.e. the spring semester):

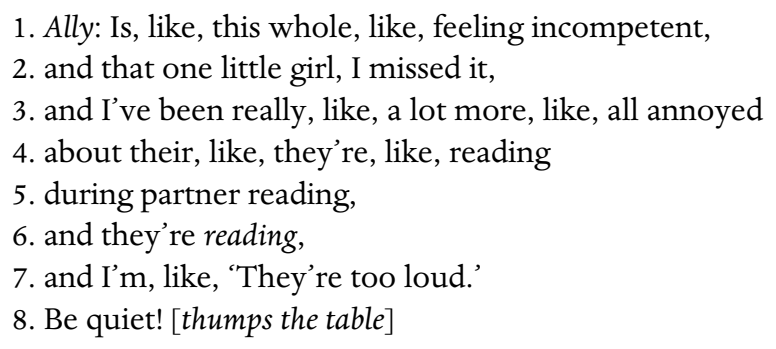

In lines 1-2, Ally states that she is feeling incompetent, and attributes this to 'missing' a student (i.e. failing to notice an academic problem right away). She follows by saying that she has been really annoyed. In line 4, she describes the actions that have arisen because of her annoyance (i.e. scolding the children because they are too loud when they are reading). Even during reading time - partner reading time - the children are being too loud, which results in a thump on the table and a stern 'Be quiet!' Given that the statement was said in the context of our discussion about standardized testing and regulations, Ally reinforces the notion that her relationship with the children is based on a shared obedience to governing systems and being an accountable teacher. She notes a sense of not doing enough (i.e. being incompetent) as she looks for ways to monitor students' off-task behavior, even when she appears to understand it is not really off-task, to make up for this feeling. Incompetence implies a fear about not being a good-enough teacher, and in order to control her own position as a good teacher, she must control the behavior of the children. As such, surveillance from institutional systems is transferred as obedience and surveillance in her relationship with the children, guided by what it means to be a competent teacher (for example, the children are quiet, on-task, and good), as is evident in Ally's comments at a time when the children are being tested and are about to transition to the next grade:

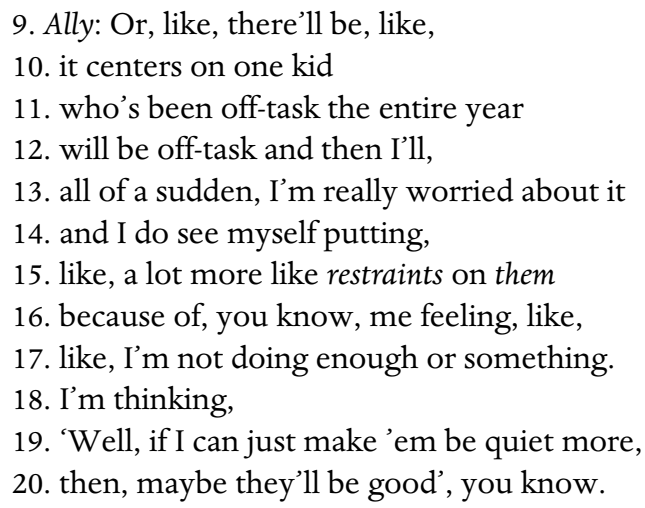

In lines 9-11, she states that her feeling of incompetence might also stem from children being offtask for the entire year. However, during this particular time of year it is intensified and she is 'all of a sudden' more worried. By using the statement 'all of a sudden', she notes that there is a distinct change in her level of worry, suggesting this emotion has not been pervasive, but rather is situational to the current academic climate. As testing time approaches, her consciousness of 
surveillance increases and that affects her interactions with the children in the classroom. Even though she has known that some children were off-task all year, she now finds herself imposing more 'restraints' to make up for her perceived incompetence. In line 17, she suggests that controlling and monitoring the children's behavior, in light of this worry, is related to feeling that she is falling short of some externalized expectation (i.e. she is not doing enough), thus taking up the position as one who needs to regulate her own and the children's actions and reactions. Ally's response to the increasing pressures of accountability is also linked to persecutory guilt as it invokes worry, self-policing and beliefs of being of inadequate (Hargreaves, 1994). If she can just make the children be quiet (i.e. placing the blame on herself), then they will be 'good' (i.e. stay on task).

There is, however, an undertone of resistance in her statement. For example, she recognizes that being annoyed by their loud reading is not realistic and rejects this position. This is illustrated in her emphasis in line 6 when she states, 'and they're reading', signifying that she understands they are actually engaging in a productive classroom activity. In addition, her ability to reflect on her annoyance, and link this to feeling incompetent, further illustrates that she recognizes this was affecting her social interactions in the classroom. She also makes visible the impossible situation she has found herself in, thus resisting a common 'guilt trap' by illustrating how she is constrained by institutional systems (Hargreaves, 1994). Resistance to this guilt trap illustrates Ally's ability to construct other ways of responding to the pressures of accountability. She acknowledges her feeling of worry, but also realizes this feeling is not necessary, rejecting the hegemony of the teacher who is driven by persecutory guilt. However, it is necessary to also note the power of accountability in her form of emotional resistance. Ally does not pose or accomplish any alternative actions that would embody active resistance, thus affirming, while at the same time rejecting, the power of the accountability climate. So, unknown is the extent to which her inactive resistance actually translates into more feelings of inadequacy and guilt.

\section{Relational Surveillance: colleague as overseer}

While Ally noted how accountability and its intensification affected her interaction with children in the classroom, Fran instead often discussed surveillance by her co-teacher. Throughout the four discussion group sessions, Fran described her co-teacher as someone who could not handle fun. This began with her story about 'fancy lunch' in the first discussion group session. In her narrative about fancy lunch, she described an elaborate pretense that accompanied lunch, in which she and the children pretended to be dressed formally and spoke with rarified English-sounding accents. She reported that she and the children got quite silly, but that she had quit playing 'fancy lunch' with the children because it disturbed her co-teacher. As such, a recurring theme for Fran was an exploration and criticism of her co-teacher's expectations, which appeared to favor strict regulation of children's emotions as well as behavior. While criticizing her co-teacher, Fran constructed an image for herself as 'the fun teacher':

1. Fran: I, I work with a co-teacher who,

2. in some ways, we're really alike and in other ways we're total opposites.

3. And so, I kind of, and this,

4. and this is kind of just me

5. in any co-teaching arrangement

6. that I've been in, is that

7. I'm the one that has more of a playful spirit,

8. like. I don't,

9. I don't wanna put anyone,

10. my co-teacher's not dour

11. in any way, but, like,

12. I'm the one that connects

13. a little bit more with the kids.

14. I'm the one that can play

15. a little bit more,

16. like, I'm more,

17. I'm gonna put the pirate costume on 
18. and I'm gonna be the captain of the ship

19. and here's all my friends and we're gonna

20. like, you know, have a pizza delivered to the pirate ship, and

21. that's my role in the classroom,

22. whereas the other teacher is more 'up-the-functioning' [sic], you know,

23. like overseer, kind of?

24. And, I don't,

25. I don't mind that that's, like,

26. I don't mind being the one that's playful but

27. some of the stress comes in

28. when the other teacher that you're working with

29. doesn't know how to do that.

In lines 1-2, Fran describes her co-teacher as someone who is both alike and opposite from her. She then continues by noting this is typical of many of her co-teaching arrangements and further suggests she has the more 'playful spirit'. She then uses a form of apology by stating in lines 8-11 that she does not want to put anyone down, but she is the one who connects more with the children. In this statement, she positions herself as a playful teacher who connects with children while simultaneously positioning her co-teacher as one who does not. She strengthens this assertion by noting the connection is related to her ability to play, which is said with an emphasis in line 14. She then provides examples of how she is more playful in lines 17-20 (having a pizza delivered, being a captain, and wearing a pirate costume), and then explicitly states that being the playful teacher is her role in the classroom. In lines 22-23, Fran contrasts her playful role with her co-teacher's role by describing her co-teacher with a phrase of her own invention, 'up-thefunctioning'. She also identifies herself in a power relationship with her co-teacher by describing her as an 'overseer'. By noting the teacher is 'up-the-functioning', Fran again strengthens her position as the playful teacher and her co-teacher's position as the one who monitors and regulates the practical functioning of the classroom. Again, this ability to be playful may be one of the assumptions that teachers make about teaching young children, given the historic and developmental value of play, and academic writing in support of a playful role.

Being positioned as 'up-the-functioning' and as an 'overseer' places the co-teacher in the role of being the watchful eye in the classroom, ensuring that standards are being met. More specifically, using the term 'overseer' implies the position of someone who manages or supervises the daily happenings in the classroom. Fran's co-teacher was not in a supervisory or administrative position, but Fran repeatedly (in several discussion groups) described her as someone who watched, judged, and evaluated her playful teacher position. Lastly, in lines 24-26, she repeats that she does not mind being the playful teacher and again takes up the position as someone who is willing to take the role opposite to the 'overseer'. Fran's continued positioning and the highlighting of the binary between herself and the co-teacher (playful/not playful) may have allowed for the space to take on this opposite role. That is, perhaps with someone else accountable, Fran could be both different and somewhat resistant.

\section{Discussion: revealing teacher emotion}

During a time often dominated by the instrumental logic of bureaucratic rationality - one which demands teachers and students to accept various standards of social efficacy and emotional control so they can become 'emotionally intelligent' or 'successful' in their professional and personal lives - an inquiry into the discourses of emotion in education renders visible the various ideologies of emotion. (Zembylas, 2007, p. xi, original emphasis)

As illustrated in the findings and noted in the quote above, the everyday emotional lives of teachers are messy, complex, and intertwined with power and ideology. In this study, we have presented an analysis of emotional themes of early educators (e.g. surveillance) and how this was linked to a discourse of emotion in education (i.e. persecutory guilt). A salient finding arising from the data was the constraints by institutional and relational systems, which led to guilt when demands were not met. This concern was replete throughout the four discussion groups and extended to various 
levels of relationships (i.e. colleagues and children). It was also made evident in the participants' representation of national figures (i.e. George Bush) and linked to national systems of accountability and assessment.

The emotions of stress, worry, and frustration that accompanied failing to meet institutional and relational standards were central for these early childhood educators. Teacher guilt pervaded the conversations and revealed a deep sense of stress as they attempted to meet the emotional and academic needs of their students, while also meeting the perceived demands placed on them by colleagues and external systems of bureaucracy. The participants revealed the power of accountability and its intensification by demonstrating how it affected their emotional life (worry/frustration), identity as a teacher (incompetent/stressed), view of their colleagues (as an overseer), and children (those who need to be regulated and monitored). As such, their emotional identities were shaped by worry about not meeting expectations and/or feelings as if they were not doing and/or being good enough, and the need to self-police their actions and their students in order to meet societal expectations.

Furthermore, when one of the teachers voiced vague complaints about accountability measures, the others usually responded with serious confirming statements, such as Joy's testimony that testing and accountability had increased significantly in the time she had been teaching. In response to Mary's exclamation that 'George is checkin' on ya', the other teachers laughed and expressed relief, signaling further affirmation about the current pressures. Early childhood education has historically been the most 'open' and least controlled classroom setting, a setting designed as child-centered and nurturing. Perhaps these responses illustrate the changing nature of the profession and how the politicization and intensification of accountability in the area of children's academic achievement have affected early childhood educators (Davies \& Bansel, 2007; Gabbard \& Atkinson, 2007).

Educators are not passive players. They notice the intensification of surveillance by social and political systems. These concerns may reflect and be especially apt for a current educational context like ours. Contemporary educational reform has become increasingly technical (i.e. focused on improving test scores) and 'top down' (Oakes \& Rogers, 2006). As with other social institutions, education has been impacted by international neo-liberal discourses that have been interpreted as policy and practice at the national and local levels (Davies \& Bansel, 2007; Spring, 2008). Neoliberal discourses have constructed the 'truth' that education must be privatized (Apple, 2001; Duncan, 2007; Spring, 2008) and intensively regulated toward market-driven outcomes (Apple, 2001; Davies \& Bansel, 2007; Spring, 2008) in order to compete in a global market. It is no surprise this would be reflected in the voices of early childhood teachers, as it has found its way into the 'common sense' constructed by others living in a neo-liberal climate. As Davies \& Bansel explain:

A particular feature of neoliberal subjects is that their desires, hopes, ideals and fears have been shaped in such a way that they desire to be morally worthy, responsibilized individuals, who, as successful entrepreneurs, can produce the best for themselves and their families. The technologies of government that have shaped these desires include a heavy investment in mechanisms of surveillance, which are tightly linked to mechanisms through which economic survival and demise are secured. (Davies $\&$ Bansel, 2007, p. 251)

In a neo-liberal era, educational reform has become associated with hierarchical systems of power and control. However, where there is oppressive power, there is often resistance (Zembylas, 2003). Increasing accountability measures that require technical surveillance may lead to discursive constructions that intensify fears and persecutory guilt, but will also create opportunities for naming and resisting systems of power. The examples reported here contain an underlying form of resistance. Although no specific action was explicitly taken by the participants, resistance was in part associated with the naming of systems of power and control that existed in their daily life (i.e. George Bush, federal mandates, and the 'overseer' colleague).

The examination of teachers' conversations outside the classroom offers opportunities to understand how teacher emotion is socially constructed and controlled and related to the discourse of emotion in educational spaces. Awareness of the emotions associated with teaching young children provides an initial understanding of classroom discourses in which teachers and children construct emotions together and/or teachers seek to regulate the emotions of children to conform to contemporary social expectations. It also provides an initial understanding about how the 
emotional landscape might be shifting under the current demands, as well as the possibility of teacher burnout if the stress, worry, and frustration of these demands are not dealt with. While we have not explicitly answered the question of how the discourse of emotion is related to the social control of emotion, we have seen a glimpse into how persecutory guilt could potentially be used as a mechanism of self-policing by institutional systems. It would be of further interest to see not only how early educators talk about emotions with each other (as in our discussion groups), but also how such themes and the discourse of emotion manifest themselves within the daily life of the classroom and the implications it may have for the overall sense of well-being in the classroom.

\section{References}

Ahmed, S. (2005) The Cultural Politics of Emotion. New York: Routledge.

Apple, M. (2001) Comparing Neo-liberal Projects and Inequality in Education, Comparative Education, 37(4), 409-423. http:/ / dx.doi.org/10.1080/03050060120091229

Bloome, D., Power Carter, S., Morton Christian, B., Madrid, S., Otto, S., Shurat-Farris, N. \& Smith, M. (2008) On Discourse Analysis: approaches to language and literacy research. New York: Teachers College Press.

Boler, M. (1999) Feeling Power: emotions and education. New York: Routledge.

Brown, K. \& Sumsion, J. (2007) Voices from the Other Side of the Fence: early childhood teachers' experiences with mandatory regulatory requirements, Contemporary Issues in Early Childhood, 8(1), 30-49. http:/ / dx.doi.org/10.2304/ciec.2007.8.1.30

Burr, V. (2003) Social Constructionism. New York: Routledge.

Cannella, G.S. (2002) Deconstructing Early Childhood Education: social justice and revolution. New York: Peter Lang.

Chubbuck, S.M. \& Zembylas, M. (2008) The Emotional Ambivalence of Socially Just Teaching: a case study of a novice urban schoolteacher, American Educational Research Journal, 45(2), 274-318. http://dx.doi.org/10.3102/0002831207311586

Colley, H. (2006) Learning to Labour with Feeling: class, gender, and emotion in childcare education and training, Contemporary Issues in Early Childhood, 7(1), 15-29. http:/ / dx.doi.org/10.2304/ ciec.2006.7.1.15

Davies, B. \& Bansel, P. (2007) Neoliberalism and Education, International Journal of Qualitative Studies in Education, 20(3), 247-259. http:/ / dx.doi.org/10.1080/09518390701281751

Davies, B. \& Harré, R. (1990) Positioning: conversation and the production of selves, Journal for the Theory of Social Behavior, 20(1), 43-63. http:/ / dx.doi.org/10.1111/j.1468-5914.1990.tb00174.x

Duncan, J. (2007) New Zealand Free Kindergartens: free or freely forgotten? International Journal of Qualitative Studies in Education, 20(3), 319-333. http:/ / dx.doi.org/10.1080/09518390701281926

Gabbard, D. \& Atkinson, T. (2007) Stossel in America: a case study of the neoliberal/neoconservative assault on public schools and teachers, Teacher Education Quarterly, 34(2), 85-109.

Gergen, K.J. (1999) An Invitation to Social Constructionism. Thousand Oaks: Sage.

Goldstein, L.S. (1997) Teaching with Love: a feminist approach to early childhood education. New York: Peter Lang.

Hargreaves, A. (1994) Changing Teachers, Changing Times: teachers' work and culture in the poststructural age. New York: Teachers College Press.

Hoy, D.C. (2004) Critical Resistance: from poststructuralism to post-critique. Cambridge, MA: MIT Press.

Lutz, C. (1988) Unnatural Emotion: everyday sentiments on a Micronesian atoll and their challenge to a western theory. Chicago: University of Chicago Press.

Lutz, C. (1990) Engendered Emotions: gender, emotion, and the rhetoric of emotional control on American discourse, in C. Lutz \& L. Abu-Lughod (Eds) Language and the Politics of Emotion, 69-91. New York: Cambridge University Press.

MacNaughton, G. (2005) Doing Foucault in Early Childhood Studies: applying poststructural ideas. London: Routledge.

Markus, H. \& Kitiyama, S. (1994) Introduction to Cultural Psychology and Emotions Research, in H. Markus \& S. Kitiyama (Eds) Emotion and Culture, 1-19. Washington, DC: American Psychological Association.

Noddings, N. (1984) Caring. Berkeley: University of California Press.

Oakes, J. \& Rogers, J. (2006) Learning Power: organizing for education and justice. New York: Teachers College Press. 
Ryan, S. \& Lobman, C. (2007) The Potential of Focus Groups to Inform Early Childhood Policy and Practice, in J.A. Hatch (Ed.) Early Childhood Qualitative Research, 63-74. New York: Routledge.

Spradley, J. (1980) Participant Observation. Belmont, CA: Wadsworth Thomson.

Spring, J. (2008) Research of Globalization and Education, Review of Educational Research, 78(2), 330-363. http: / / dx.doi.org/10.3102/0034654308317846

Zembylas, M. (2003) Interrogating 'Teacher Identity': emotion, resistance, and self -formation, Educational Theory, 53(1), 107-127. http:// dx.doi.org/10.1111/j.1741-5446.2003.00107.x

Zembylas, M. (2005) Discursive Practices, Genealogies, and Emotional Rules: a poststructuralist view on emotion and identity in teaching, Teaching and Teacher Education, 21(8), 935-948. http: / / dx.doi.org/10.1016/j.tate.2005.06.005

Zembylas, M. (2007) Five Pedagogies, a Thousand Possibilities: struggling for hope and transformation in education. Rotterdam: Sense.

SAMARA MADRID is an Assistant Professor in the Elementary and Early Education Department at the University of Wyoming, Laramie, USA. Her research has focused on the ethnographic study of early childhood education with an emphasis on exploring how emotions guide classroom communication and gender roles within school and peer culture. Correspondence: Samara Madrid, Assistant Professor of Early Childhood Education, Elementary and Early Education Department, University of Wyoming, McWhinnie Hall 305, 1000 E. University Avenue, Laramie, WY 82071, USA (smadrid3@uwyo.edu).

MAYLAN DUNN-KENNEY is an Associate Professor in the Department of Teaching and Learning at Northern Illinois University, DeKalb, USA. Her research has focused on social aspects of teaching and learning, particularly in multicultural and cross-cultural contexts. Correspondence: Maylan Dunn-Kenney, Associate Professor of Early Childhood Education, Department of Teaching and Learning, Northern Illinois University, Gabel 166, DeKalb, IL 60115, USA (mdunn@niu.edu). 